\title{
PREVALENCE OF VARIOUS TWO DIMENSIONAL ECHOCARDIOGRAPHIC FINDINGS IN PATIENTS WITH COPD AND ITS CORRELATION WITH DISEASE SEVERITY
}

\author{
Irfan Ismail Ayub1, Abdul Majeed Arshad², Shalu S Thomas³, Hemanth Laksmaiah4, Dhanasekar Thangaswamy5 \\ ${ }^{1}$ Assistant Professor, Department of Pulmonary Medicine, Sri Ramachandra Medical College and Research Institute, Chennai. \\ ${ }^{2}$ Assistant Professor, Department of Pulmonary Medicine, Sri Ramachandra Medical College and Research Institute, Chennai. \\ ${ }^{3}$ Respiratory Therapist, Pushpagiri Institute of Medical Sciences, Thiruvalla, Kerala. \\ ${ }^{4}$ Assistant Professor, Department of Pulmonary Medicine, East Point College of Medical Sciences, Bangalore, Karnataka. \\ 5 Professor, Department of Pulmonary Medicine, Sri Ramachandra Medical College and Research Institute, Chennai.
}

\section{ABSTRACT}

\section{BACKGROUND}

Mild-to-moderate pulmonary hypertension is a common complication of chronic obstructive pulmonary disease (COPD) and is associated with increased rates of exacerbation and decreased survival. The aim of our study was to find the prevalence of pulmonary hypertension and other cardiac abnormalities in patients with COPD and identify any correlation with disease severity, as well as identify any clinical predictors of pulmonary hypertension in these patients.

\section{MATERIALS AND METHODS}

All patients presenting to our hospital with clinical symptoms suggestive of COPD were subjected to spirometry. For all patients, a detailed clinical history and disease severity assessment by GOLD and CAT were available. Two-dimensional echocardiography was performed for all patients and findings were recorded. Prevalence values for the various echocardiographic findings were calculated and correlation with disease severity was analysed.

\section{RESULTS}

Out of the total of 50 patients studied, $82 \%$ were male, $58 \%$ were aged above 60 years, $70 \%$ were ex-smokers and $88 \%$ were symptomatic (mMRC $\geq 2$ ). The majority had high CAT scores $(\geq 21,62 \%)$, were in GOLD 3 or $4(68 \%)$, and were predominantly in group D of the Individualised Assessment (IA) of COPD classification (62\%) as per the GOLD statement. Right atrium (RA) and right ventricle (RV) dilatation were seen in $28 \%$ and $20 \%$ of the study group respectively. Tricuspid regurgitation and pulmonary hypertension were seen in $48 \%$ and $50 \%$ of the study population. Grade 1 left ventricular diastolic dysfunction (LVDD) and left ventricular hypertrophy ( $\mathrm{LVH})$ were seen in $86 \%$ and $58 \%$ of the patients. There was significant correlation between all the three echocardiographic findings and mMRC. There was significant correlation between TR and CAT scores $(p=0.041)$, between PH and Grade 1 LVDD and GOLD stage ( $p=0.029$ and $p=0.001$, respectively), and between PH and Grade 1 LVDD and IA of COPD ( $p=$ 0.029 and $\mathrm{p}=0.015$, respectively).

\section{CONCLUSION}

Pulmonary hypertension is common in patients with COPD and correlates well with symptoms (mMRC) and severity of disease (GOLD).

\section{KEYWORDS}

COPD, Echocardiography, Pulmonary Hypertension.

HOW TO CITE THIS ARTICLE: Ayub II, Arshad AM, Thomas SS, et al. Prevalence of various two dimensional echocardiographic findings in patients with COPD and its correlation with disease severity. J. Evolution Med. Dent. Sci. 2017;6(76):5443-5447, DOI: $10.14260 /$ Jemds/2017/1181

\section{BACKGROUND}

COPD is associated with significant extrapulmonary (systemic) effects among which cardiac manifestations are most common. Cardiovascular disease accounts for approximately $50 \%$ of all hospitalisation and nearly one third of all deaths.[1] In more advanced diseases,

Financial or Other, Competing Interest: None.

Submission 14-08-2017, Peer Review 09-09-2017,

Acceptance 15-09-2017, Published 21-09-2017.

Corresponding Author:

Irfan Ismail Ayub,

Assistant Professor

Department of Pulmonary Medicine,

First Floor Link, G Block, Sri Ramachandra

Medical College and Research Institute,

Porur, Chennai-600116, India.

E-mail: iia@rediffmail.com

DOI: $10.14260 /$ jemds/2017/1181

(c) (i) $\$$ cardiovascular disease accounts for $20 \%-25 \%$ of all deaths in COPD.[2] COPD affects pulmonary blood vessels, right ventricle, as well as left ventricle leading to development of pulmonary hypertension, cor pulmonale, right ventricular dysfunction, and left ventricular dysfunction too. Echocardiography provides a rapid, non-invasive portable and accurate method to evaluate the right ventricle function, right ventricular filling pressure.

Mild-to-moderate pulmonary hypertension is a common complication of chronic obstructive pulmonary disease (COPD). Pulmonary hypertension usually worsens during exercise, sleep and exacerbation. Pulmonary vascular remodelling in COPD is the main cause of increase in pulmonary artery pressure and is thought to result from the combined effects of hypoxia, inflammation and loss of capillaries in severe emphysema. [3] Pulmonary hypertension is associated with increased risks of exacerbation and decreased survival.[4] 
Hence, it is imperative to identify pulmonary hypertension in patients with COPD at the earliest and take steps in aggressively managing the airflow limitation in these patients and consider supplementary oxygen therapy if indicated. The aim of our study was to find the prevalence of pulmonary hypertension and other cardiac abnormalities in patients with COPD and correlate them with severity of COPD. Our secondary objective was to see if we could identify any clinical predictor of pulmonary hypertension in patients with COPD.

\section{MATERIALS AND METHODS}

This prospective descriptive study was conducted at the Department of Pulmonary Medicine at Sri Ramachandra Medical University. Approval was obtained from the Ethics Committee of our university. Our university hospital is a large tertiary referral centre for the city of Chennai in the state of Tamilnadu in India. Spirometry was performed as a routine investigation for patients who presented to our outpatient services with dyspnoea, wheeze or chest tightness. Prior to spirometry, a detailed clinical history (including symptoms and smoking history) was obtained, and clinical examination findings were recorded. For all patients, modified Medical Research Council (mMRC) dyspnoea score and COPD Assessment Test (CAT) scores were available. For reasons of convenience, all patients who had a post-bronchodilator FEV1/FVC $<70 \%$ and were diagnosed with COPD in the study period from December 2016 to April 2017 were included in the study. They were then subjected to 2 dimensional echocardiography (2D ECHO, VIVID E9) and findings were recorded. Informed written consent was obtained from all patients.

\section{Spirometry}

For all patients, a FVC manoeuvre was performed in the Pulmonary Function Testing Laboratory of the department using a flow based pneumotachometer-spirometer (model KoKo Px, company nSpire). The following spirometric indices were recorded: $\mathrm{FEV}_{1}, \mathrm{FVC}, \mathrm{FEV}_{1} / \mathrm{FVC}$ and the absolute volume as well as the percentage reversibility in $\mathrm{FEV}_{1}$ and FVC. Patients were encouraged to perform the test to ensure that optimum results were achieved as per the American Thoracic Society-European Respiratory Society (ATS-ERS) guidelines in force since 2005.[5] This included achieving a target expiratory time of six or more seconds, and repeating the test a minimum of three times, and up to a maximum of 8 times but no more, to achieve a minimum of at least 3 technically acceptable and reproducible results. The highest measurements from the best 3 results were taken. Predicted percentage values of $\mathrm{FEV}_{1}, \mathrm{FVC}$, and $\mathrm{FEV}_{1} / \mathrm{FVC}$ were calculated using the software in the spirometer. The spirometer was frequently calibrated to ensure performance as per the laboratory protocol. A post-bronchodilator value of $\mathrm{FEV}_{1} / \mathrm{FVC}<70 \%$ was diagnosed as obstructive pattern, and with appropriate history and clinical findings, a diagnosis of COPD was made. The severity of COPD was classified as per GOLD staging, including the Individualised Assessment of COPD grade.[6]

\section{D Echocardiography}

During Echocardiography, the following were assessed and recorded-
1. Pericardium.

2. Left and right side chamber size (atrial and ventricle).

3. Pulmonary hypertension (PH) - mild, moderate or severe.

4. Tricuspid regurgitant flow - presence or absence.

5. The anatomy and function of the other valves - presence or absence of stenosis or regurgitation.

6. Cardiac function (Ejection Fraction, EF) and Diastolic Dysfunction.

Tricuspid regurgitant flow was identified by colour flow Doppler technique and the maximum jet velocity was measured by continuous wave Doppler without the use of intravenous contrast.

Right ventricular systolic pressure was estimated based on the modified Bernoulli equation and was considered to be equal to the SPAP in the absence of right ventricular outflow obstruction: $\mathrm{SPAP}(\mathrm{mmHg})=$ right ventricular systolic pressure $=$ trans-tricuspid pressure gradient $(\mathrm{TTPG})+$ right atrial pressure (RAP), where trans-tricuspid gradient is $4 \mathrm{v} 2$ ( $\mathrm{v}=$ peak velocity of tricuspid regurgitation, $\mathrm{m} / \mathrm{s}$ ). [7]

Pulmonary hypertension (PH) was defined in this study as $\mathrm{SPAP} \geq 30 \mathrm{mmHg}$. ${ }^{8]}$ This value was chosen according to the definition of pulmonary hypertension. $\mathrm{H}$ was classified into mild, moderate, and severe category as sPAP 30-49, 50-69 and $>70 \mathrm{mmHg}$, respectively (using Chemla formula, mean pulmonary arterial pressure (MPAP) $=0.61 \mathrm{sPAP}+2 \mathrm{mmHg}$ and putting value of $25-35,35-45$, and $>45 \mathrm{mmHg}$ of MPAP for mild, moderate, and severe pulmonary hypertension, respectively).[9]

Right ventricle dimension was measured by M-Mode echo and right ventricular dilation or cor pulmonale was said to be present when it exceeded the normal range of $0.9-2.6 \mathrm{~cm}$.

Right ventricular systolic dysfunction was said to be present when it was hypokinetic.

Left Ventricular Function was assessed by using the Following Parameters-

1. EF (Ejection Fraction) $=$ measure of how much end diastolic value is ejected from left ventricle (LV) with each contraction (normal is $56 \%-78 \%$ ).

2. FS (Fractional Shortening) - it is a percentage change in LV dimension with each LV contraction (Normal is $28 \%$ $44 \%)$.

3. E/A - diastolic filling of left ventricles usually classified initially on the basis of the peak mitral flow velocity of the early rapid filling wave (E), divided by peak velocity of the late filling wave caused by atrial contraction (A). In normal subjects, $\mathrm{LV}$ elastic recoil is vigorous because of normal myocardial relaxation, therefore more filling is completed during early diastolic. Left ventricular diastolic dysfunction (LVDD) is said to be present when E/A is $<1.3$ (age group $45-49$ years), $<1.2$ (Age group $50-59$ years), $<1.0$ (age group $60-69$ years), and $<0.8$ (age group $\geq 70$ years).[10]

Results of the spirometry and 2D echocardiography findings, along with other patient details were recorded in patient specific proforma. Statistical analysis was performed using Stata statistical analysis software. A descriptive analysis was performed. Categorical variables were expressed as frequency (percentages), and quantitative 
variables were expressed as mean \pm SD (standard deviation), or median (IQR, interquartile range). Statistical significance was calculated using Pearson's Chi Square test, and results were deemed significant if $p$ value was less than 0.05 .

\section{RESULTS}

A total of 50 patients were diagnosed with COPD during a period of 4 months (January 2016 to April 2016) and were recruited into the study. The majority of them were male (82\%), aged above 60 years (58\%), were ex-smokers $(70 \%)$ and were symptomatic (mMRC 2 or more, 88\%). Severity of COPD grading was reasonably similar within the group as per the various severity assessment grading systems used. The majority had high CAT scores (21\% to $30.44 \%)$, were in GOLD 3 or $4(68 \%)$, and were predominantly in group D of the Individualised Assessment (IA) of COPD classification $(62 \%)$ as per the GOLD statement. Right atrium (RA) and right ventricle (RV) dilatation were seen in $28 \%$ and $20 \%$ of the study group respectively. Tricuspid regurgitation (TR) was seen $48 \%$ of the patients, with the majority having mild TR (32\%). Pulmonary hypertension (PH) was seen in $50 \%$ of the study group with the majority having mild PH (30\%). Grade 1 left ventricular diastolic dysfunction (LVDD) and left ventricular hypertrophy ( $\mathrm{LVH}$ ) were seen in $86 \%$ and $58 \%$ of the patients. The baseline characteristics of the study group is summarised in Table 1.

Correlation between various echocardiographic parameters (PH, TR and Grade 1 LVDD) and symptoms (mMRC) and severity of COPD (CAT, GOLD, and IA of COPD) were performed and are shown in Tables 2 to 5 . There was significant correlation between all the three echocardiographic findings and mMRC. There was significant correlation between TR and CAT scores $(p=0.041)$, between PH and Grade 1 LVDD and GOLD stage ( $p=0.029$ and $p=$ 0.001 , respectively), and between PH and Grade 1 LVDD and IA of COPD ( $\mathrm{p}=0.029$ and $\mathrm{p}=0.015$, respectively).

\begin{tabular}{|c|c|}
\hline Total Number of Patients & 50 \\
\hline \multicolumn{2}{|l|}{ Sex } \\
\hline Male & $41(82)$ \\
\hline Female & $9(18)$ \\
\hline \multicolumn{2}{|l|}{ Age (Years) } \\
\hline$<40$ & $1(2)$ \\
\hline 41 to 50 & $8(16)$ \\
\hline 51 to 60 & $9(18)$ \\
\hline 61 to 70 & $19(38)$ \\
\hline 71 to 80 & $10(20)$ \\
\hline$>80$ & $3(6)$ \\
\hline Height (Centimetre) & 162.1 (140 to 183$)$ \\
\hline Weight (Kilogram) & 59.9 (35 to 113$)$ \\
\hline BMI & $22.8(12$ to 37$)$ \\
\hline History of Systemic Hypertension & $24(48)$ \\
\hline \multicolumn{2}{|c|}{ Smoking History } \\
\hline Non-smoker & $12(24)$ \\
\hline Ex-smoker & $35(70)$ \\
\hline Current Smoker & $3(6)$ \\
\hline \multicolumn{2}{|l|}{ CAT Score } \\
\hline Mild (5 to 10) & $1(2)$ \\
\hline Moderate (11 to 20$)$ & $18(36)$ \\
\hline High (21 to 30 ) & $22(44)$ \\
\hline
\end{tabular}

\begin{tabular}{|c|c|}
\hline Very High (> 30) & $9(18)$ \\
\hline \multicolumn{2}{|l|}{ mMRC Score } \\
\hline 0 (Normal) & $0(0)$ \\
\hline 1 (Mild) & $6(12)$ \\
\hline 2 (Moderate) & $35(70)$ \\
\hline 3 (Severe) & $9(18)$ \\
\hline 4 (Very Severe) & $0(0)$ \\
\hline \multicolumn{2}{|l|}{ GOLD } \\
\hline 1 & $4(8)$ \\
\hline 2 & $12(24)$ \\
\hline 3 & $16(32)$ \\
\hline 4 & $18(36)$ \\
\hline \multicolumn{2}{|c|}{ Individualised Assessment of COPD } \\
\hline A & $3(6)$ \\
\hline $\mathrm{B}$ & $14(28)$ \\
\hline $\mathrm{C}$ & $2(4)$ \\
\hline $\mathrm{D}$ & $31(62)$ \\
\hline \multicolumn{2}{|c|}{ Echocardiographic Findings } \\
\hline RA Dilatation & $14(28)$ \\
\hline RV Dilatation & $10(20)$ \\
\hline LA Dilatation & $10(20)$ \\
\hline LV Dilatation & $8(16)$ \\
\hline \multicolumn{2}{|c|}{ Tricuspid Regurgitation } \\
\hline Mild & $16(32)$ \\
\hline Moderate & $6(12)$ \\
\hline Severe & $2(4)$ \\
\hline \multicolumn{2}{|c|}{ Pulmonary Artery Pressure } \\
\hline Normal & $25(50)$ \\
\hline Mild & $15(30)$ \\
\hline Moderate & $7(14)$ \\
\hline Severe & $3(6)$ \\
\hline Left Ventricular Diastolic Dysfunction & $43(86)$ \\
\hline Left Ventricular Hypertrophy & $29(58)$ \\
\hline \multicolumn{2}{|c|}{$\begin{array}{l}\text { Table 1. Baseline Characteristics } \\
\text { of the Study Group }(n=50)\end{array}$} \\
\hline
\end{tabular}

Values expressed as n (\%), or mean (SD), or median (min., $\max$.

\begin{tabular}{|c|c|c|c|c|c|}
\hline \multirow{2}{*}{$\begin{array}{l}\text { mMRC } \\
\text { Score }\end{array}$} & \multicolumn{4}{|c|}{ Pulmonary Artery Pressure (PAP) } & \multirow{2}{*}{$\begin{array}{c}\text { Pearson } \\
\text { Chi } \\
\text { Square }\end{array}$} \\
\hline & Normal & Mild & Moderate & Severe & \\
\hline Mild & 5 & 0 & 1 & 6 & \multirow{3}{*}{0.032} \\
\hline Moderate & 18 & 13 & 2 & 35 & \\
\hline \multirow[t]{3}{*}{ Severe } & 2 & 2 & 4 & 9 & \\
\hline & \multicolumn{4}{|c|}{ Tricuspid Regurgitation (TR) } & \\
\hline & Normal & Mild & Moderate & Severe & \\
\hline Mild & 5 & 0 & 1 & 0 & \multirow{3}{*}{0.005} \\
\hline Moderate & 20 & 13 & 1 & 1 & \\
\hline \multirow[t]{3}{*}{ Severe } & 1 & 3 & 4 & 1 & \\
\hline & \multicolumn{4}{|c|}{$\begin{array}{l}\text { Grade } 1 \text { Left Ventricular Diastolic } \\
\text { Dysfunction (LVDD) }\end{array}$} & \\
\hline & \multicolumn{2}{|c|}{ Yes } & \multicolumn{2}{|l|}{ No } & \\
\hline Mild & \multicolumn{2}{|c|}{3} & \multicolumn{2}{|l|}{3} & \multirow{3}{*}{0.025} \\
\hline Moderate & \multicolumn{2}{|c|}{32} & \multirow{2}{*}{\multicolumn{2}{|c|}{$\frac{3}{1}$}} & \\
\hline Severe & \multicolumn{2}{|c|}{8} & & & \\
\hline & 2. Cc & 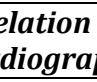 & etween $m M$ & $(n=$ & \\
\hline
\end{tabular}




\begin{tabular}{|c|c|c|c|c|c|}
\hline \multirow{2}{*}{$\begin{array}{l}\text { CAT } \\
\text { Score }\end{array}$} & \multicolumn{4}{|c|}{ Pulmonary Artery Pressure (PAP) } & \multirow{2}{*}{$\begin{array}{c}\text { Pearson } \\
\text { Chi } \\
\text { Square }\end{array}$} \\
\hline & Normal & Mild & Moderate & Severe & \\
\hline Mild & 1 & 0 & 0 & 0 & \multirow{4}{*}{0.184} \\
\hline Moderate & 11 & 6 & 1 & 0 & \\
\hline Severe & 10 & 8 & 2 & 2 & \\
\hline \multirow[t]{3}{*}{$\begin{array}{c}\text { Very } \\
\text { severe }\end{array}$} & 3 & 1 & 4 & 1 & \\
\hline & \multicolumn{4}{|c|}{ Tricuspid Regurgitation (TR) } & \\
\hline & Normal & Mild & Moderate & Severe & \\
\hline Mild & 1 & 0 & 0 & 0 & \multirow{4}{*}{0.041} \\
\hline Moderate & 13 & 4 & 1 & 0 & \\
\hline Severe & 10 & 10 & 1 & 1 & \\
\hline \multirow[t]{3}{*}{$\begin{array}{c}\text { Very } \\
\text { severe }\end{array}$} & 2 & 2 & 4 & 1 & \\
\hline & \multicolumn{4}{|c|}{$\begin{array}{l}\text { Grade } 1 \text { Left ventricular diastolic } \\
\text { dysfunction (LVDD) }\end{array}$} & \\
\hline & \multicolumn{2}{|c|}{ Yes } & \multicolumn{2}{|c|}{ No } & \\
\hline Mild & \multicolumn{2}{|l|}{1} & \multicolumn{2}{|l|}{0} & \multirow{4}{*}{0.195} \\
\hline Moderate & 13 & & 5 & & \\
\hline Severe & 21 & & 1 & & \\
\hline $\begin{array}{l}\text { Very } \\
\text { severe }\end{array}$ & \multicolumn{2}{|l|}{8} & \multicolumn{2}{|l|}{1} & \\
\hline & $\begin{array}{l}\text { le 3. Co } \\
\text { Echoca }\end{array}$ & Ite & $\begin{array}{l}\text { tween C } \\
\text { Finding }\end{array}$ & cores & \\
\hline
\end{tabular}

\begin{tabular}{|c|c|c|c|c|c|}
\hline \multirow{2}{*}{$\begin{array}{l}\text { Gold } \\
\text { Stage }\end{array}$} & \multicolumn{4}{|c|}{ Pulmonary Artery Pressure (PAP) } & \multirow{2}{*}{$\begin{array}{c}\text { Pearson } \\
\text { Chi } \\
\text { Square }\end{array}$} \\
\hline & Normal & Mild & Moderate & Severe & \\
\hline Mild & 4 & 0 & 0 & 0 & \multirow{4}{*}{0.029} \\
\hline Moderate & 10 & 2 & 0 & 0 & \\
\hline Severe & 6 & 7 & 3 & 0 & \\
\hline \multirow[t]{3}{*}{$\begin{array}{l}\text { Very } \\
\text { Severe }\end{array}$} & 5 & 6 & 4 & 3 & \\
\hline & \multicolumn{4}{|c|}{ Tricuspid Regurgitation (TR) } & \\
\hline & Normal & Mild & Moderate & Severe & \\
\hline Mild & 4 & 0 & 0 & 0 & \multirow{4}{*}{0.078} \\
\hline Moderate & 9 & 3 & 0 & 0 & \\
\hline Severe & 9 & 5 & 2 & 0 & \\
\hline \multirow[t]{3}{*}{$\begin{array}{l}\text { Very } \\
\text { Severe }\end{array}$} & 4 & 8 & 4 & 2 & \\
\hline & \multicolumn{4}{|c|}{$\begin{array}{l}\text { Grade } 1 \text { Left Ventricular Diastolic } \\
\text { Dysfunction (LVDD) }\end{array}$} & \\
\hline & \multicolumn{2}{|c|}{ Yes } & \multicolumn{2}{|c|}{ No } & \\
\hline Mild & \multicolumn{2}{|c|}{1} & \multicolumn{2}{|c|}{3} & \multirow{4}{*}{0.001} \\
\hline Moderate & \multicolumn{2}{|c|}{11} & \multicolumn{2}{|c|}{1} & \\
\hline Severe & \multicolumn{2}{|c|}{13} & \multicolumn{2}{|c|}{3} & \\
\hline $\begin{array}{l}\text { Very } \\
\text { severe }\end{array}$ & \multicolumn{2}{|c|}{18} & \multicolumn{2}{|c|}{0} & \\
\hline & $\begin{array}{l}\text { e 4. Co } \\
\text { Echoc }\end{array}$ & (necto & $\begin{array}{l}\text { tween } G \\
\text { ic Findin }\end{array}$ & $\begin{array}{l}\text { D Stage } \\
(n=50)\end{array}$ & \\
\hline
\end{tabular}

\begin{tabular}{|c|c|c|c|c|c|}
\hline \multirow{2}{*}{$\begin{array}{l}\text { IA of } \\
\text { COPD } \\
\text { Grade }\end{array}$} & \multicolumn{4}{|c|}{ Pulmonary Artery Pressure (PAP) } & \multirow{2}{*}{$\begin{array}{c}\text { Pearson } \\
\text { Chi } \\
\text { Square }\end{array}$} \\
\hline & Normal & Mild & Moderate & Severe & \\
\hline Mild & 3 & 0 & 0 & 0 & \multirow{4}{*}{0.029} \\
\hline Moderate & 12 & 2 & 0 & 0 & \\
\hline Severe & 1 & 0 & 1 & 0 & \\
\hline $\begin{array}{c}\text { Very } \\
\text { Severe }\end{array}$ & 9 & 13 & 6 & 3 & \\
\hline & \multicolumn{4}{|c|}{ Tricuspid Regurgitation (TR) } & \\
\hline & Normal & Mild & Moderate & Severe & \\
\hline Mild & 3 & 0 & 0 & 0 & \multirow{4}{*}{0.122} \\
\hline Moderate & 11 & 3 & 0 & 0 & \\
\hline Severe & 1 & 0 & 1 & 0 & \\
\hline Very & 11 & 13 & 5 & 2 & \\
\hline
\end{tabular}

\begin{tabular}{|c|c|c|c|}
\hline Severe & & & \\
\hline & $\begin{array}{c}\text { Grade 1 Left Ventricular } \\
\text { Diastolic Dysfunction (LVDD) }\end{array}$ & \\
\hline & Yes & No & \\
\hline Mild & 1 & 2 & \multirow{2}{*}{0.015} \\
\hline Moderate & 12 & 2 & \\
\hline Severe & 1 & 1 & 2 \\
\cline { 1 - 3 } Very & 29 & \multicolumn{2}{|c|}{2} \\
Severe & \multicolumn{3}{|c|}{$\begin{array}{c}\text { Table 5. Correlation between Individualised } \\
\text { Assessment (IA) of COPD Grade and }\end{array}$} \\
Echocardiographic Findings (n = 50)
\end{tabular}

\section{DISCUSSION}

Use of echocardiography based cardiac evaluation in COPD to evaluate the status PH and other concomitant cardiac lesions, is very valuable in the management of COPD.[11] In our study, Grade 1 LVDD was present in $86 \%$ of patients. $50 \%$ of our patients had $\mathrm{PH}$ and $48 \%$ of them had tricuspid regurgitation (TR). Our study had a higher prevalence of Grade 1 LVDD. One study from India showed $47.5 \%$ patients had LVDD, $42.5 \%$ patients had $\mathrm{PH}$ and $67.5 \%$ of patients had measurable tricuspid regurgitation (TR).[12]

The level of $\mathrm{PH}$ has a prognostic value in patients with COPD as demonstrated by several studies with 5-year survival rates varying as low as $50 \%$ in patients with mild $\mathrm{PH}$ (20-30 $\mathrm{mmHg}), 30 \%$ in those with moderate-to-severe $\mathrm{PH}$ (30-50 mmHg), and $0 \%$ in the small group of patients with very severe $\mathrm{PH}(>50 \mathrm{mmHg}$ ). Thus, a high degree of $\mathrm{PH}$ bears a poor prognosis.[13] In our study, the severity of PH increased with severity of COPD. $50 \%$ of our patients had echocardiographic findings of $\mathrm{PH}$. This is similar to the prevalence results of earlier studies. The frequencies of $\mathrm{PH}$ in mild, moderate and severe COPD were $30 \%, 14 \%$, and $6 \%$ respectively in our study group. In one study, it was found to be $25 \%, 43 \%$, and $68 \%$ in mild, moderate, and severe COPD, respectively.[14] Left ventricular hypertrophy (LVH) was present in $58 \%$ of our patients in our study. This is similar to earlier studies where LVH was found in $25 \%-60 \%$ patients with COPD.[15]

In our study, severity of COPD (GOLD score) correlated significantly with PH and grade 1 LVDD. However, there was no statistical significant correlation between GOLD score and TR. N K Gupta et al have reported similar findings in their study where there was a linear relationship between severity of COPD (GOLD score) and PH and Grade 1 LVDD.[12] Our study also showed significant correlation between IA of COPD score with PH and Grade 1 LVDD. There are no earlier studies that have compared IA of COPD with PH and Grade 1 LVDD. Now with the latest GOLD guidelines moving away from applying spirometry derived airflow limitation and GOLD scores subsequently, in the IA of COPD grading, our study has importance as it shows that IA of COPD alone (in the absence of spirometry, where facilities for the latter are limited) can be taken as a screening tool to predict patients with COPD likely to have $\mathrm{PH}$ and then refer these patients for 2D ECHO to centres where facilities are available.

In our study, we found that there was significant correlation between mMRC score and PH, TR, and Grade 1 LVDD. We could not find any other studies that looked at correlation between mMRC score and these 2D ECHO variables. We believe our result has importance especially in low cost settings like in the Indian subcontinent, where we 
can suggest using the mMRC scores as a screening tool to predict possibility of coexisting cardiac abnormalities, especially PH. Patients with higher mMRC scores can then be advised to undergo a 2D ECHO to rule out PH. Also in our study, though correlation between CAT score and TR was statistically significant, there was no statistical significance seen in between CAT score and the two other 2D ECHO variables, namely $\mathrm{PH}$ and Grade 1 LVDD. Thus, based on our study, we cannot recommend using CAT scores alone as a predictor of possibly coexisting $\mathrm{PH}$.

Our study is not without limitations. Our study population was small and was not representative of the population, leading to referral bias. Also, being a small study population, true prevalence rates cannot be ascertained. Majority of our patients had severe disease, and hence were more likely to have PH. Higher scores of IA of COPD implies higher exacerbation rates, which is known to correlate with $\mathrm{PH}$ as well and hence may not add new information to what earlier studies have shown. But our study has brought out this relationship between IA of COPD and $\mathrm{PH}$ hence reinforcing the application of IA of COPD in addition to MMRC as screening for $\mathrm{PH}$ in patients with COPD.

\section{CONCLUSION}

Our study shows high prevalence of pulmonary hypertension, and left ventricular dysfunction in patients with COPD, especially with more severe COPD. We suggest screening of all COPD patients with 2D ECHO. In settings where 2D ECHO is not easily available or Cardiology services are already overloaded with clinical work and where this might not be possible, we suggest using a simple mMRC score along with IA of COPD score to screen patients who may be having $\mathrm{PH}$ and send those patients with mMRC scores 2 or more or IA of COPD group D, for 2D ECHO. This would contribute to the assessment of prognosis in these patients and assist in identifying individuals likely to suffer from increased mortality and morbidity warranting close monitoring and intensive treatment.

\section{REFERENCES}

[1] Anthonisen NR, Connett JE, Kiley JP, et al. Effects of smoking intervention and the use of an inhaled anticholinergic bronchodilator on the rate of decline of FEV1. The lung health study. JAMA 1994;272(19):1497-505.

[2] Sin DD, Anthonisen NR, Soriano JB, et al. Mortality in COPD: role of comorbidities. Eur Respir J 2006;28(6):1245-57.
[3] Chaouat A, Savale L, Chouaid C, et al. Role for interleukin-6 in COPD-related pulmonary hypertension. Chest 2009;136(3):678-87.

[4] Kwon YS, Chi SY, Shin HJ, et al. Plasma C-reactive protein and endothelin-1 level in patients with chronic obstructive pulmonary disease and pulmonary hypertension. J Korean Med Sci 2010;25(10):1487-91.

[5] Miller MR, Crapo R, Hankinson J, et al. General considerations for lung function testing. Eur Respir J 2005;26(1):153-61.

[6] GOLD COPD. (Global strategy for diagnosis, management and prevention of COPD) 2017. www.goldcopd.org.

[7] Yock PG, Popp RL. Noninvasive estimation of right ventricular systolic pressure by Doppler ultrasound in patients with tricuspid regurgitation. Circulation 1984;70(4):657-62.

[8] Bredikis AJ, Liebson PR. The echocardiogram in COPD: estimating right heart pressures. J Respir Dis 1998;19:191-8.

[9] Chemla D, Castelain V, Humbert M, et al. New formula for predicting mean pulmonary artery pressure using systolic pulmonary artery pressure. Chest 2004;126(4):1313-7.

[10] Libby P, Bonow RO, Zipes DP, et al. Braunwald's heart disease. $8^{\text {th }}$ edn. Philadelphia: Saunders 2008:P 251.

[11] Arcasoy SM, Christie JD, Ferrari VA, et al. Echocardiographic assessment of pulmonary hypertension in patients with advanced lung disease. Amer J Respir Crit Care Med 2003;167(5):735-40.

[12] Gupta NK, Agrawal RK, Srivastav AB, et al. Echocardiographic evaluation of heart in chronic obstructive pulmonary disease patient and its correlation with the severity of disease. Lung India 2011;28(2):105-9.

[13] Oswald-Mammosser M, Weitzenblum E, Quoix E, et al. Prognostic factors in COPD patients receiving longterm oxygen therapy. Importance of pulmonary artery pressure. Chest 1995;107(5):1193-8.

[14] Higham MA, Dawson D, Joshi J, et al. Utility of echocardiography in assessment of pulmonary hypertension secondary to COPD. Eur Respir J 2001;17(3):350-5.

[15] Poddar AK, Chakraborti BN, Ghosh JL, et al. Assessment of left ventricular function in patients of COPD. Ind J Tub 1997:44-181. 